\title{
Biosorption of Fe (II) and Cd (II) ions from aqueous solution using a low cost Adsorbent from Orange Peels
}

\author{
${ }^{* 1}$ ADEBAYO, GB; ${ }^{2}$ MOHAMMED, AA; ${ }^{3}$ SOKOYA, SO \\ Department of Industrial Chemistry, Faculty of Physical Sciences, University of Ilorin, Kwara State, Nigeria \\ Department of Chemistry, Faculty of Physical Sciences, University of Ilorin, Kwara State Nigeria \\ Corresponding author email: adebayochem@gmail.com
}

\begin{abstract}
The peels from orange are less expensive biomaterials with excellent adsorption capacities. Orange peels were carbonized at $450{ }^{\circ} \mathrm{C}$, purified, activated with orthophosphoric acid and modified with citric acid to obtain Modified and Activated carbon which were used as low cost adsorbent to adsorb $\mathrm{Cd}(\mathrm{II})$ and $\mathrm{Fe}(\mathrm{II})$ metal ions. The effects of initial metal ions concentration; $\mathrm{pH}$; temperature; contact time; and adsorbents dose on the removal of metal ions were investigated. The maximum adsorption occurs at $26^{\circ} \mathrm{C}$ and decreased with increase in temperature while optimum adsorption took place at $\mathrm{pH}$ of 6 . Both the Fe-MOP and Fe-AOP system attained equilibrium in 60 minutes but Cd-MOP \& Cd-AOP attained equilibrium at $45 \mathrm{mins}$. The enthalpy of adsorption ranged from $2.48 \mathrm{KJ} / \mathrm{mol}$ to $14.418 \mathrm{KJ} / \mathrm{mol}$ and the entropy of adsorption ranged from $-3.53 \mathrm{KJ} / \mathrm{mol}$ to $41.07 \mathrm{KJ} / \mathrm{mol}$ for both adsorbents (MOP and AOP). The kinetic studies showed that the adsorption process fitted well for pseudo-second order rate expression. Both MOP and AOP has much affinity for Fe(II) uptake than $\mathrm{Cd}(\mathrm{II})$ ion and the adsorption data fitted most into Freundlich but the highest adsorption capacity of 0.895 was obtained from Temkin. The presence of hydroxyl, alkyl, ether and aldehyde groups was confirmed by Infrared while the SEM shows porous surface characteristics suitable for adsorption. ( ) JASEM

http://dx.doi.org/10.4314/jasem.v20i3.25
\end{abstract}

Keywords: Modified Orange peel, adsorbent dose, Isotherm, adsorption, Activated Orange peel

Contamination by heavy metals through various human activities in the environment poses a lot of risk to both fauna and flora habitation. Adsorption of heavy metals using various agricultural waste byproducts as a low cost adsorbent can reduce the pollution caused by these metals. Discharge of heavy metals as part of industrial waste required recycling methods in order to conserve the essential metals (Jothinayagi and Anbazhagan, 2009). Biosorption can be defined as the use of biological materials that form complexes with metal ions using their functional groups (Krishnani et al., 2008). Sequestering of metal by different part of cells can occur using various processes such as complexation, chelation, ion exchange, coordination, precipitation and reduction (Wase and Forster, 1997).

Various health effects are associated with accumulation of heavy metals such as lead, antimony, mercury, manganese, chromium, cadmium, copper, e.t.c., because they are non-biodegradable and significantly toxic to both living organism and ecological environments (Doris et al., 2000). Toxic metals are often removed by several methods such as evaporation, fitration, oxidation- reduction processes, ion exchange or reverse osmosis, electrochemical treatment but these methods produced a lot of disadvantages such as low efficiency, high energy and chemical requirements, and usually produce large amounts of sludge (Radhika et al., 2006). The use of new technology such as adsorption with low cost adsorbent to remove heavy metals using agricultural waste have been studied and recommended by various researchers. Example of these low cost adsorbent includes coconut husk (Agbozu and Emoruwa 2014; Okoli and Ezuma 2014), sawdust ( Bulut and Tez 2007), wheat bran (Bulut and Baysal, 2006), rice husk (Singh and Singh, 2012), melon husk (Giwa et al., 2013). The major advantage of low cost adsorbent from agricultural waste over conventional methods in the removal of heavy metals includes high efficiency in metal recovery, readily available, highly economical and environmental friendly, minimization of biological and chemical sludge ( Hanif et al., 2010; Muneer et al., 2010).This research work investigated the effectiveness of produced modified adsorbent and activated carbon from orange peels which were used in removing heavy metals. The characterization of the adsorbent were examined using Scanning electron microscopy (SEM) and Fourier transmission InfraRed Spectroscopy (FTIR) Thermodynamics and Kinetics model were used to evaluate the adsorption process of the heavy metals. 


\section{MATERIALS AND METHOD}

Adsorbent Preparation: The Orange peels were collected from Ipata market in Ilorin, Kwara State, Nigeria The raw material (orange peels) collected were dried at low temperature $\left(<105^{\circ} \mathrm{C}\right)$ for $48 \mathrm{hrs}$ to remove moisture content.

Preparation of Modified Orange Peels (MOP): 50g dried sample was grounded to pass through mesh sizes of $0.3-0.6 \mathrm{~mm}$ (300-600micron). The grounded- sieved sample was soaked in excess $0.3 \mathrm{M}$ $\mathrm{HNO}_{3}$ for $24 \mathrm{hrs}$ at room temperature. This was followed by washing the sample severally with deionized water (until $\mathrm{pH}$ of 6.8 is obtained). The sample was then filtered and air dried. The air dried biomass was steeped in $0.3 \mathrm{M}$ citric acid overnight. The citric acid modified sample was washed until the flushing water has a $\mathrm{pH}$ of 7 . They were finally air dried and kept in tight container .

Preparation of Activated Orange Peels (AOP): 500g sample (orange peels) was weighed into a crucible and then pack into the muffle furnace. The sample was carbonized at $450{ }^{\circ} \mathrm{C}$ for 20 minutes. The carbonized samples were grounded into a granulated size with a mortar and pestle to reduce particle size and improve the surface area and the sample were also purified by placing $100 \mathrm{~g}$ of carbonized sample in $500 \mathrm{ml}$ of $0.5 \mathrm{M} \mathrm{HCL}$ and transferred to $1000 \mathrm{ml}$ beaker and the mixture was heated and stirred. The mixture were then filtered and washed with distilled water and dried at $105{ }^{\circ} \mathrm{C}$. The purified sample was then added to $400 \mathrm{ml}$ of $1 \mathrm{M}$ solution of orthophosphoric acid and the mixture were stirred with a mechanical shaker for 2 hours. (Adegoke et al., 2010)

\% Yield of Carbonized Product from the Raw Material:100g of dried orange peel was carbonized separately and cooled in the dessiccator. The carbonized sample was weighed until a constant weight was obtained. The \%yield was calculated from the weight obtained.

$\%$ Yield $=\frac{\text { Weight } A X 100}{\text { weight } B}$

$\mathrm{W}_{\mathrm{A}}, \mathrm{w}$ в represents weight of carbonized materials and weight of raw material

Characterization of Physical Properties of Adsorbent Determination of moisture content of MOP and AOP: 2g samples (Modified and Activated Orange peels) were weighed into a crucible of known weight and placed in the oven thermo-regulated at $105^{\circ} \mathrm{C}$ for $3 \mathrm{hrs}$. The samples was removed after $3 \mathrm{hrs}$ and cooled in the desiccator. The cooled sample was weighed and returned back to the oven for $30 \mathrm{mins}$ at $105^{\circ} \mathrm{C}$. The sample was removed, cooled in the desiccator and reweighed. This was repeated until a constant weight was obtained. The \% Moisture Content (\% M.C) was then calculated.

$\% \mathrm{M} . \mathrm{C}=\frac{\mathrm{W}_{1}-\mathrm{W}_{2}}{\mathrm{~W}_{1}-\mathrm{W}_{0}} \mathrm{X} 100$

$\mathrm{W}_{0}, \mathrm{~W}_{1}, \mathrm{~W}_{2}$ represents weight of empty crucible, crucible + sample and crucible + sample after heating.

Determination of ash content of MOP and AOP: An empty dry crucible was weighed and $2 \mathrm{~g}$ of sample was weighed into it. The crucible was place in a furnace and was heated at $450^{\circ} \mathrm{C}$ for $2 \mathrm{hrs}$. It was then cooled in the desiccator and re-weighed. The \% ash content (A.C \%) were calculated using the formula below :

$\%$ A.C $=\frac{\mathrm{W}_{2}-\mathrm{W}_{0}}{\mathrm{~W}_{1}-\mathrm{W}_{0}} \times 100$

$\mathrm{W}_{0 \text {, w1, w2 }}$ represents weight of empty crucible, crucible + sample and crucible + sample after heating.

Determination of Bulk Density of MOP and AOP: The bulk density (B.D) of the samples were determined by using Archimedes' principle by weighing an empty measuring cylinder, and the weight of the cylinder containing water filled to the brim was also taken. The measuring cylinder was dried and the sample (M $\mathrm{OP}$ and $\mathrm{AOP}$ ) were packed into it, leveled and weighed. The weight of the sample packed in the measuring cylinder was determined from the difference in weight of the filled and empty measuring cylinder. The volume of water in the container was determined by taking the difference in weight of the empty and water filled empty measuring cylinder.

B.D $=\frac{\mathrm{W}_{2}-\mathrm{W}_{0}}{\mathrm{~W}_{1}-\mathrm{W}_{0}}$

$\mathrm{W}_{0, \mathrm{w} 1}, \mathrm{~W}_{2}$ represent weight of empty dried measuring cylinder, empty dried cylinder + water filled to the brim, dried cylinder + Sample

Determination of $p H$ of $M O P$ and $A O P$ : The $\mathrm{pH}$ of the various adsorbents was determined by preparing a suspension of each sample (MOP \& AOP) in ratio $1: 2$. This was carried out by weighing $2 \mathrm{~g}$ of each sample and adding $4 \mathrm{ml}$ of distilled water in a conical flask. The mixture was agitated on a mechanical shaker for $15 \mathrm{mins}$ to attain equilibrium. The $\mathrm{pH}$ of the resulting suspension was determined using a $\mathrm{pH}$ meter. 
Fourier Transform Infrared (FTIR) Analysis of MOP and Effect of $p H$ on the adsorption of MOP and AOP: $A O P$ :FTIR was also adopted to reveal the functional group $25 \mathrm{ml}$ of the solution with the equilibrium present in both adsorbents using Agilent Cary 630 FTIR concentration (40 \& 50ppm) of $\mathrm{Cd}(\mathrm{II})$ and $\mathrm{Fe}(\mathrm{II})$ spectrophotometer in the range of 400 to $4000 \mathrm{~cm}^{-1}$ in the solution was prepared and pippetted into 6 different transmittance mode.

Scanning Electron Microscopy (SEM) Analysis of $M O P$ and AOP: SEM also used to show the size of the micro-pores of the samples (morphology and shape of adsorbents) using Phenom Scanning Electron Microscope, Model Pro X. Before the analysis, the adsorbents were sputtered with thin gold layer to avoid electrostatic charging during examination

Instrumentation: An Atomic Adsorption Spectrometer (Buck scientific model 210VGP) were used for determining the metals concentrations. A Hanna Instrument $\mathrm{pH} 211$ microprocessor meters was used for $\mathrm{pH}$ measurements. SHZ-82 Thermostatic water bath shaker XMTD-204 shaker was used for agitating the samples.

Batch Adsorption Studies: Batch adsorption experiments were conducted to study optimum removal capacity of heavy metals from an aqueous solution. $0.1 \mathrm{~g}-0.5 \mathrm{~g}$ different doses of MOP and AOP were added to bottle containing $25 \mathrm{ml}$ of the aqueous solution of iron and cadmium. The bottles were kept in orbital shaker at $30^{\circ} \mathrm{C}$ temperature at 160r.p.m. The contents were filtered using whatman No. 41 filter paper. The equilibrium time and optimum dose adsorbent were optimized by repeating the same experiment at different conditions. The metal concentration retained in the adsorbent phase was calculated using the equation below:

$$
q_{e}=\frac{V\left(C_{i}-C_{f}\right) \times 10^{-3}}{M}
$$

Where $\mathrm{q}_{\mathrm{e}}$ is the amount adsorbed $(\mathrm{mg} / \mathrm{g}) \mathrm{C}_{\mathrm{i}}$ is the initial metal ion concentration in $\mathrm{ppm}, \mathrm{C}_{\mathrm{f}}$ is equilibrium concentration of metal ions in $\mathrm{ppm}, \mathrm{V}$ is thb volume of the solution $(\mathrm{ml})$ and $\mathrm{W}$ is the mass of th adsorbent ( $\mathrm{g})$.

Effect of Temperature on the adsorption of MOP and $A O P$ : Effect of temperature on the extent of solute adsorption were investigated systematically at different temperatures $\left(26,50,70^{\circ} \mathrm{C}\right)$ under the selected agitation time (120mins) and dose of adsorbents $(0.2 \mathrm{~g})$.
$100 \mathrm{ml}$ capacity conical flask and the initial $\mathrm{pH}$ measured. The initial $\mathrm{pH}$ in each was varied between $2-12$ by the addition of $0.1 \mathrm{M} \mathrm{HCL}$ and $0.1 \mathrm{M} \mathrm{NaOH}$ solution. $0.2 \mathrm{~g}$ adsorbent was added and the mixture was equilibrated for $120 \mathrm{mins}$. After equilibrium the mixture was filtered and the filtrate was analyzed by AAS (Eliagwu et al., 2009).

Effect of Contact Time on the adsorption of MOP and $A O P: 25 \mathrm{ml}$ of the solution with the equilibrium concentration $(40 \& 50 \mathrm{ppm})$ was transferred into 6 different bottles, covered and labeled. $0.2 \mathrm{~g}$ each of the adsorbent was weighed into the labeled bottles, agitated at $32^{\circ} \mathrm{C}$ in a shaker for different contact times (35, 45, 60, 120, 180mins). After each agitated time, the content of each flask was filtered. (Eliagwu et al., 2009)

Effect of Dosage of Adsorbents on the adsorption of $M O P$ and AOP: The different doses of adsorbent namely MOP and AOP taken such as $0.1 \mathrm{~g}$ to $0.5 \mathrm{~g}$ with $25 \mathrm{ml}$ of iron and cadmium aqueous solution in a polyethylene bottle in an orbital shaker at about $30^{\circ} \mathrm{C}$ and 160rpm. (Eliagwu et al., 2009)

Effect of Adsorbate Initial Concentration: 25ml of several prepared solutions with concentrations 10, 20, $30,40,50$ and $60 \mathrm{ppm}$ were measured into a $120 \mathrm{~mL}$ capacity bottle, $0.2 \mathrm{~g}$ of the adsorbent was added into each and agitated using an orbital shaker vibrating at $160 \mathrm{rpm}$ for $120 \mathrm{mins}$ each. At the end of the time the content of the bottle were filtered and analyzed (Eliagwu et al., 2009).

\section{RESULT AND DISCUSSION}

The adsorbents were characterized by $\%$ yield, moisture contents, pH, bulk density and ash contents as shown in thatable 1 below. Bulk density is high in MOP than AOP thecause higher density provides greater volume and hormally indicates better quality adsorbent. Higher density adsorbent need not be regenerated as frequently because it holds more adsorbate per unit volume (Itodo et al.,2010). AOP has a lower moisture content and ash content which is an indication of effective adsorptive properties. High moisture and ash content will block the active site of the adsorbent. $\mathrm{pH}$ is affected by degree of ionization in which polar solute will be strongly adsorbed from a non-polar solvent by polar adsorbent (Walter et al.,2005). Based on the result below MOP show a good adsorptive properties due to the presence of citric acid which aid binding during adsorption. 
Table 1: Physical Properties Of Adsorbent (MOP and AOP)

\begin{tabular}{lll}
\hline PROPERTIES & MOP & AOP \\
\hline$\%$ Yield & - & 31.17 \\
Moisture Content $(\%)$ & 15 & 10 \\
pH & 4.7 & 3.2 \\
Bulk Density $(\mathrm{g} / \mathrm{ml})$ & 0.39 & 0.23 \\
Ash content $(\%)$ & 40 & 50 \\
\hline
\end{tabular}

Effect of Temperature on Adsorption: The temperature is an important parameter in the context of adsorption and has two major effects on the adsorption process. Increasing the temperature is known to increase the rate of diffusion of the adsorbate molecules across the boundary layer and in the internal pores of the solution. In addition, temperature will change the equilibrium capacity of the adsorbent for a particular adsorbate (Wang et al, 2005). As the temperature increases the percentage adsorption decreases in accordance with Le Chartelier's principle. The decrease in percentage uptake may be due to a decreased equilibrium constant for adsorption at higher temperature. The equilibrium capacity of adsorption in a given system is thus found to decrease with increasing temperature. Based on this work, the removal rate of Fe-MOP, CdAOP and Cd-MOP all increased with increasing temperature [except for Fe-AOP which showed a negative heat of reaction $(-\Delta \mathrm{H})$ indicating that the adsorption were endothermic process $(\Delta \mathrm{H}$ were positive values).

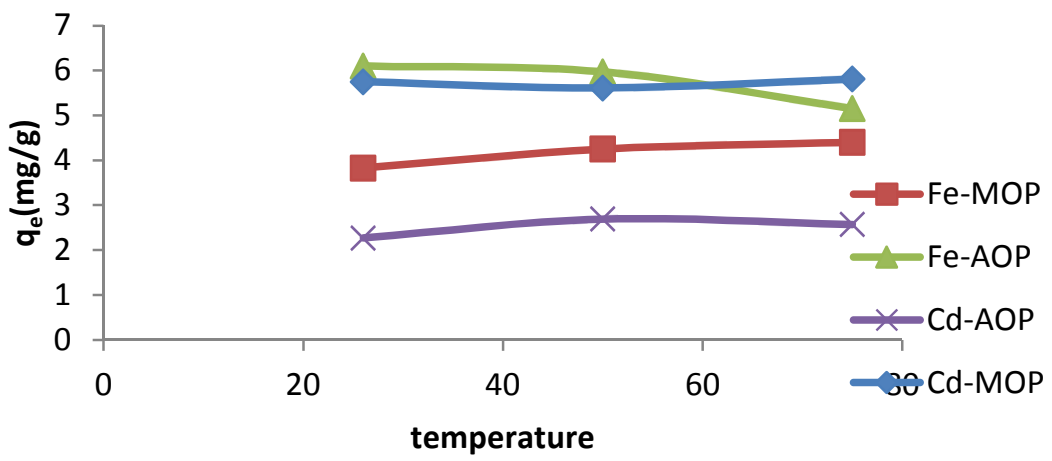

Fig 1 : Effect of temperature on adsorption process

Effect of contact time on Adsorption: Effects of contact time on the removal of iron and cadmium were illustrated in Fig. 2. It was observed that the Iron and cadmium removal increased with contact time and equilibrium adsorption was established within 60mins (Fe-MOP and Cd-AOP systems) and 45mins (Fe-AOP and Cd-MOP system). Metal ions at initial concentration of Fe-MOP and Cd-AOP was obtained at $40 \mathrm{mg} / \mathrm{L}$; Fe-AOP and Cd-MOP was obtained at $50 \mathrm{mg} / \mathrm{L}$. It was very clear from these results that the contact time required for maximum uptake of metal ions concentration by orange peels was dependent on the initial metal ion concentration. Cadmium and Iron removal were highly concentration dependent. 


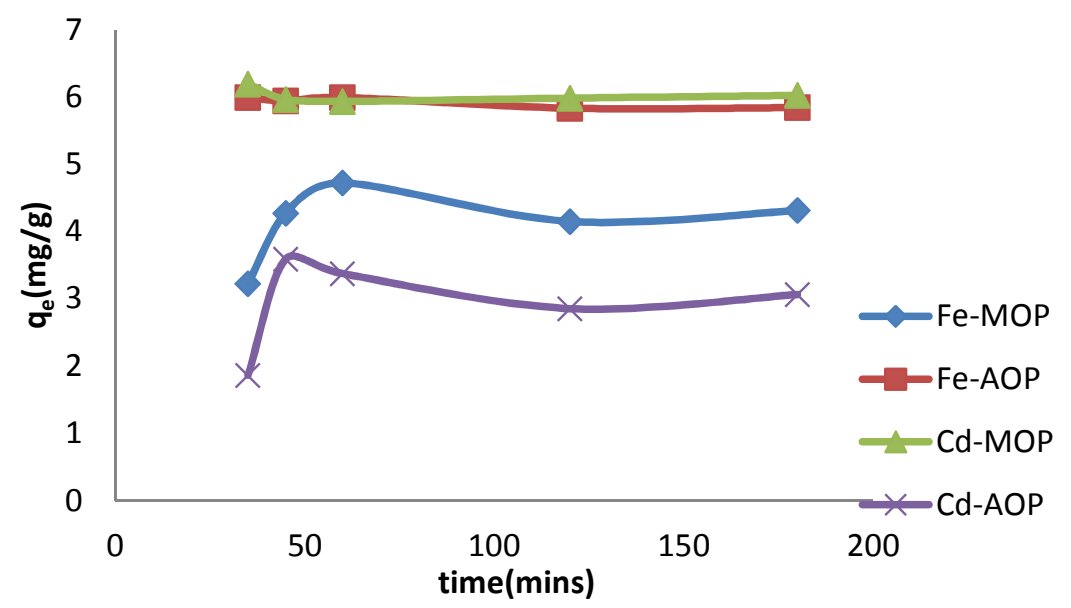

Fig 2: Effect of contact time on $\mathrm{Fe}(\mathrm{II})$ and $\mathrm{Cd}(\mathrm{II})$ on MOP and AOP

Effect of Dosage of Adsorbents on Adsorption: The removal of iron and cadmium on both MOP and AOP adsorbents both decreased with increasing dosage of the adsorbents from $0.1-0.5 \mathrm{~g}$, recording maximum adsorption capacity at $0.1 \mathrm{~g}$ as shown in fig. 3 below. However, competition for bonding sites between molecules of the adsorbate should decrease with increase in dosage of the adsorbents. (Elaigwu et al., 2009)

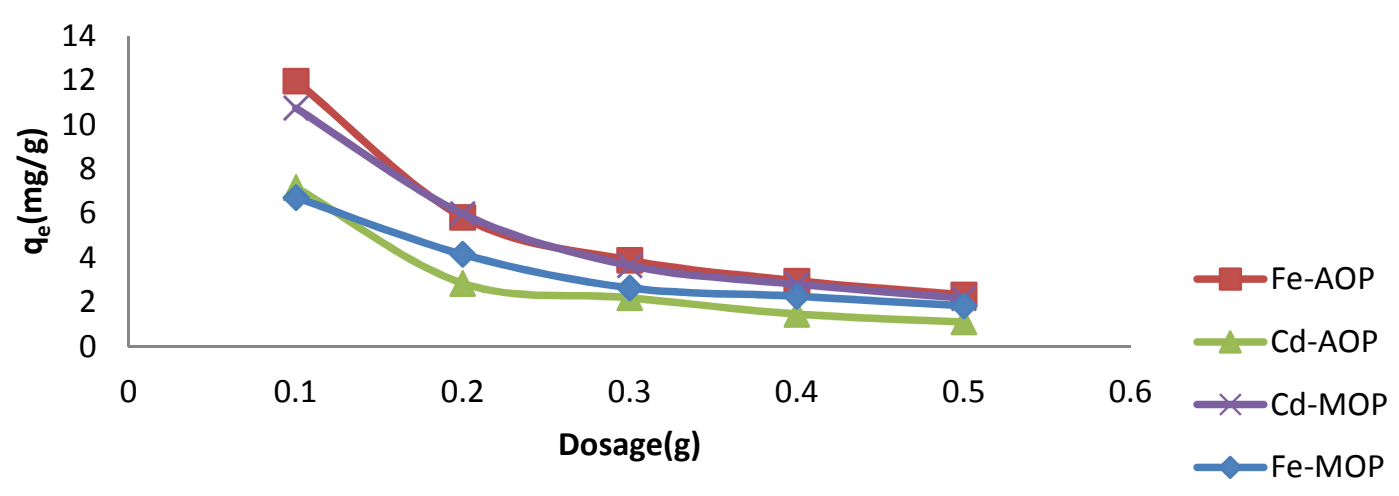

Fig.3: Effect of adsorbent dosage on Fe(II) AND Cd(II) adsorption on MOP and AOP

Effect of PH on Adsorption: It was observed that the $\mathrm{pH}$ was affected by the amount of cadmium and iron adsorbed as shown in fig.4. The adsorption of both cadmium and iron MOP were found to increase with increasing $\mathrm{pH}$ from 2 to 6 having the maximum removal at $\mathrm{pH}$, with the exception of Cd-AOP system which decreased at $\mathrm{pH} 2$ to 4 and later increase from 6-12. The increase in metal ion removal as $\mathrm{pH}$ increases could be explained on the basis of a decrease in competition between hydroxonium ions and metal species for the surface sites and also by the decrease in positive surface charge on the adsorbents, which resulted in a lower electrostatic repulsion between the surface and the metal ions and hence uptake of metal ions increased. A similar theory was proposed by several earlier workers for metal adsorption on different adsorbents (Acar and Eren, 2006; Patnukao et al., 2008). 


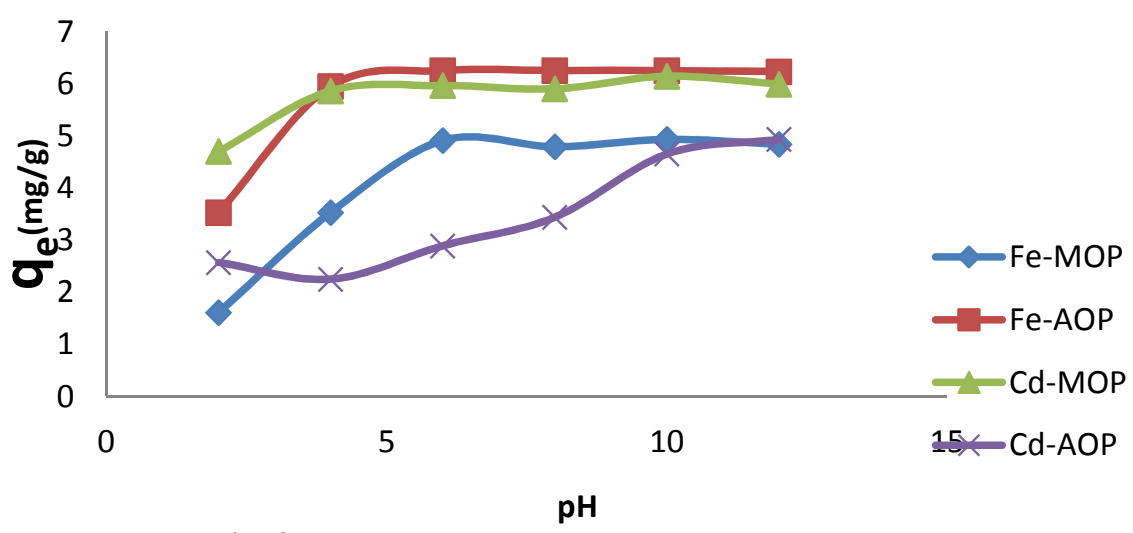

Fig.4 : Effect of pH on adsorption of $\mathrm{Fe}(\mathrm{II})$ and $\mathrm{Cd}(\mathrm{II})$ on MOP $\&$ AOP

Effect of initial Metal Concentration on adsorption: The effects of initial metal concentration on the adsorption of $\mathrm{Fe}$ (III) and Cd (II) ions onto biosorbents are shown in fig. 5. The amount of metal ion adsorbed by both adsorbents increased with increasing initial metal concentration. Two main factors are responsible for increase in initial metal concentration which includes; high probability of collision between metal ions with the biosorbent surface and high rate of metal ions diffusion onto biosorbent surface (Wiwid et al ., 2014).

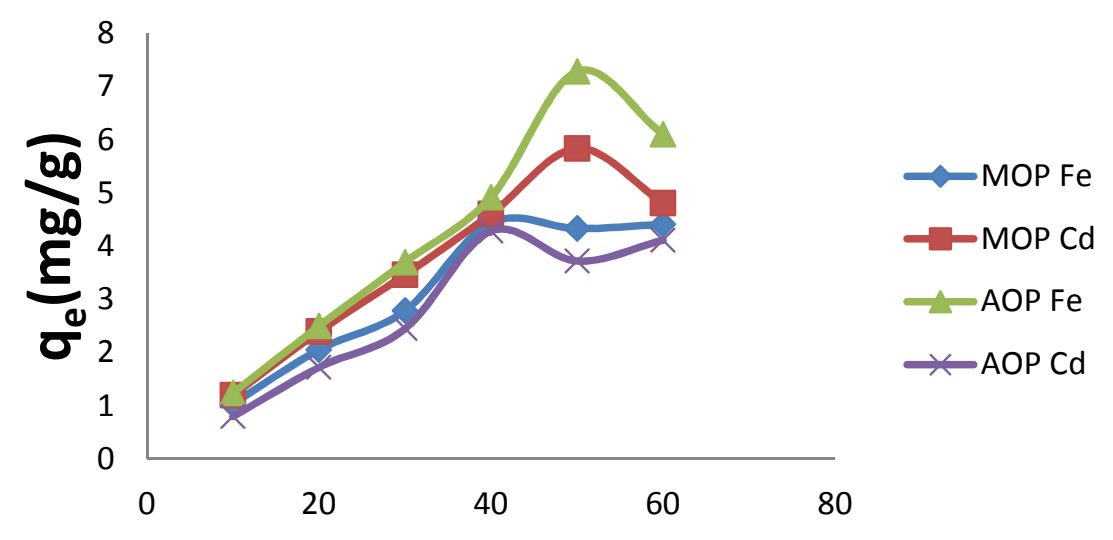

Fig. 5: Effect of initial metal on adsorption of $\mathrm{Fe}(\mathrm{II})$ and $\mathrm{Cd}(\mathrm{II})$ on MOP \& AOP

Thermodynamics Study: A study of the temperature dependence of adsorption reaction gives valuable knowledge about the enthalpy and entropy changes during adsorption. The standard Gibbs free energy change $\left(\Delta \mathrm{G}^{0}\right)$ is the fundamental criterion of spontaneity of a process and can be determined using equilibrium constant $\left(\mathrm{K}_{\mathrm{c}}\right)$ by equation

Where $q_{e}$ and $C_{e}$ represent the concentration of solute on the adsorbent and in the solution, respectively. The standard enthalpy change $\left(\Delta \mathrm{H}^{\circ}\right)$ and standard entropy change $\left(\Delta S^{0}\right)$ were given by Van't-hoff equation that showed the dependence of equilibrium constant of the adsorption process on the temperature.

$\Delta \mathrm{G}^{\mathrm{o}}=\Delta \mathrm{H}^{\mathrm{o}}-\mathrm{T} \Delta \mathrm{S}^{\mathrm{o}} \ldots$ (3)
$\Delta \mathrm{G}^{\mathrm{o}}=-\mathrm{RT} \ln \mathrm{K}_{\mathrm{c} . \ldots} \quad(1)$

Where $\mathrm{R}$ is the universal gas constant and $\mathrm{T}$ is the temperature in Kelvin $(\mathrm{K})$. The equilibrium constant $\mathrm{K}_{\mathrm{c}}$, the Langmuir adsorption constant, can be calculated as $\mathrm{K}_{\mathrm{c}}=\frac{\mathrm{qe}}{\mathrm{Ce}}$.

$\ln K_{c}=\frac{\Delta S}{R}+\frac{\Delta H}{R T}$

The plot of $\operatorname{lnk}_{\mathrm{c}}$ vs $1 / \mathrm{T}$ was found to be linear for all system; hence the $\Delta \mathrm{H}^{\mathrm{o}}$ and $\Delta \mathrm{S}^{\mathrm{o}}$ could be calculated from the intercept and slope of the plot $\operatorname{lnk}_{\mathrm{c}} \mathrm{vs} 1 / \mathrm{T}$ and the thermodynamic parameters $\left(\Delta \mathrm{G}^{\mathrm{o}}, \Delta \mathrm{H}^{\mathrm{o}}, \Delta \mathrm{S}^{\mathrm{o}}\right)$ at a temperature of $298 \mathrm{~K}$ were listed in the table 2 below 
. The standard Gibbs free energy change $\Delta \mathrm{G}^{0}$ at all temperatures was negative for Cd-MOP confirming that the adsorption of cadmium onto modified orange peel Cd-MOP was spontaneous and thermodynamically favorable. The more negative the $\Delta \mathrm{G}^{\mathrm{o}}$, the stronger driving force of adsorption reaction and vice versa. The standard enthalpy change $\Delta \mathrm{H}^{\circ}$ were positive (except for Fe-AOP system) making them endothermic process. The positive adsorption standard entropy change $\Delta \mathrm{S}^{\circ}$ of $\mathrm{Fe}-\mathrm{MOP}$ and $\mathrm{Cd}-$ MOP may be interrelated to the increased randomness at the solid-liquid interface.

Table 2: Thermodynamic calculation for $\mathrm{Fe}$ and $\mathrm{Cd}$ on the adsorption of MOP and AOP

\begin{tabular}{|c|c|c|c|c|}
\hline & Fe-MOP & Fe-AOP & Cd-MOP & Cd-AOP \\
\hline $\begin{array}{l}\Delta \mathrm{H} \\
(\mathrm{KJ} / \mathrm{mol})\end{array}$ & 14.418 & -37.65 & 2.48 & 4.40 \\
\hline $\begin{array}{l}\Delta \mathrm{S} \\
(\mathrm{J} / \mathrm{mol} / \mathrm{K})\end{array}$ & 41.07 & -110.94 & 10.60 & -3.53 \\
\hline $\begin{array}{l}\Delta \mathrm{G} \\
(\mathrm{KJ} / \mathrm{mol})\end{array}$ & -12224.442 & $2 \quad 33022.47$ & -3156.32 & 1056.34 \\
\hline $\mathrm{R}^{2}$ & 0.972 & 0.928 & 0.219 & 0.508 \\
\hline
\end{tabular}

Adsorption Isotherm: The adsorption data were subjected to different adsorption isotherms namely Langmuir, Freundlich and Temkin which were used to test the equilibrium relationship between amount of $\mathrm{Fe}$ (II) and $\mathrm{Cd}$ (II) ions adsorbed on AOP and MOP, the equilibrium concentration of metal ions and maximum adsorption capacity of AOP and MOP.

Langmuir isotherm: The Langmuir isotherm is valid for sorption of a solute from a liquid solution as monolayer adsorption on a surface containing a finite number of identical sites. The Langmuir equation is written as $\mathrm{c}_{\mathrm{e}}$

$\mathrm{C}_{\mathrm{e}} / \mathrm{q}_{\mathrm{e}}=\mathrm{c}_{\mathrm{e}} / \mathrm{q}_{\mathrm{m}}+1 / \mathrm{q}_{\mathrm{m}} \mathrm{b} \ldots(5)$

$\mathrm{C}_{\mathrm{e}}(\mathrm{mg} / \mathrm{L})$ is the equilibrium concentration; $\mathrm{q}_{\mathrm{e}}$ is the amount of ion adsorbed on MOP and AOP at equilibrium, $\mathrm{q}_{\mathrm{m}}$ and $\mathrm{b}$ are Langmuir constants related to capacity and energy of adsorption respectively. Figs. 6-8 shows the Langmuir, Freundlich and Temkin isotherm of adsorption using both adsorbents. A plot of $\mathrm{C}_{\mathrm{e}} / \mathrm{q}_{\mathrm{e}}$ vs $\mathrm{C}_{\mathrm{e}}$ indicates a straight line of slope $1 / \mathrm{q}_{\mathrm{m}}$ and intercept of $1 / \mathrm{bq}$.

Freundlich isotherm: The Freundlich isotherm model is an empirical equation that is used for non-ideal sorption involving heterogenous sorption. It is given as: $\log \mathrm{q}_{\mathrm{e}}=\log \mathrm{k}_{\mathrm{f}}+\operatorname{nlog}_{\mathrm{e}} \ldots$ (6)

$\mathrm{k}_{\mathrm{f}}$ is the adsorption coefficient, $\mathrm{n}$ indicates the adsorption intensity.

Temkin isotherm:Temkin describes the behaviour of adsorption on heterogenous surfaces.

It is given by: $\mathrm{q}_{\mathrm{e}}=\mathrm{a}+\mathrm{b} \log \mathrm{C}_{\mathrm{e}} \ldots \ldots \ldots$ (7)

Where $a$ and $b$ were obtained from the intercept and slope of $\mathrm{q}_{\mathrm{e}} \mathrm{vs} \log \mathrm{C}_{\mathrm{e}}$ which were related to adsorption capacity and intensity of adsorption. The Langmuir, Freundlich and Temkin isotherm parameters for $\mathrm{Fe}$ and $\mathrm{Cd}$ adsorption onto AOP and MOP at different temperature were given in Table 3. The correlation coefficient of Freundlich was closer to unity when compared with others; hence the Freundlich isotherm was more satisfying to fit the equilibrium adsorption data of $\mathrm{Cd}$ and $\mathrm{Fe}$ for the temperature than others. $\mathrm{k}_{\mathrm{f}}$ increases with temperature indicate the adsorption process of $\mathrm{Fe}$ and $\mathrm{Cd}$ was endothermic. For values of $0.1<1 / \mathrm{n}<1$, the adsorption is favourable and that adsorption capacity is only slightly suppressed at lower equilibrium concentration. This isotherm does not predict any saturation of the adsorption by the sorbate, this infinite surface coverage is predicted mathematically, indicating multilayer adsorption on the surface. 


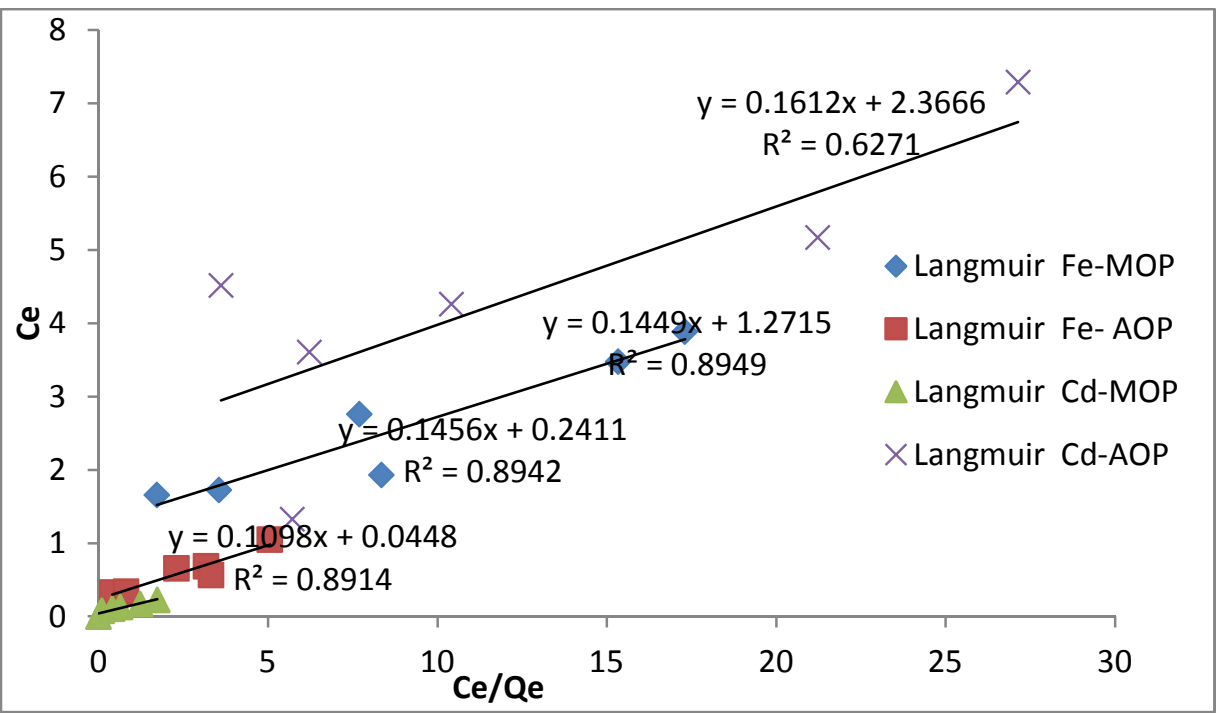

Fig.6: Langmuir isotherm for Fe and Cd adsorption on MOP and AOP

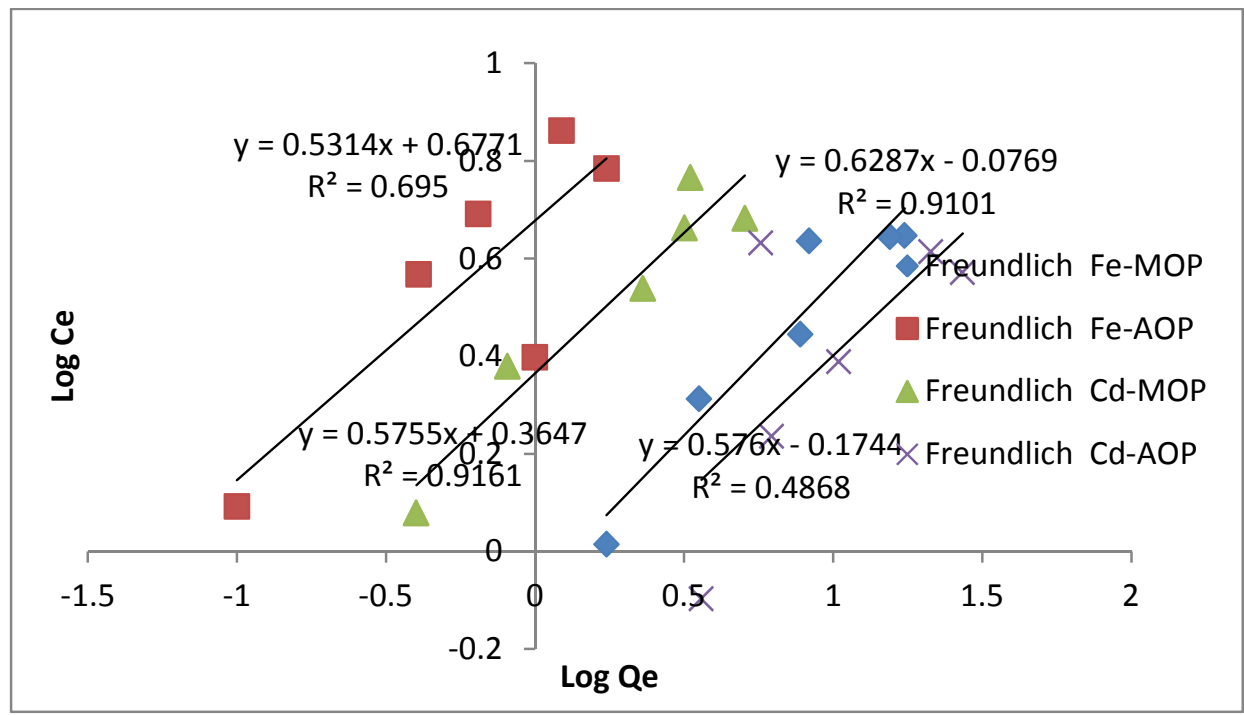

Fig.7: Freundlich isotherm for Fe and $\mathrm{Cd}$ adsorption on MOP and AOP 


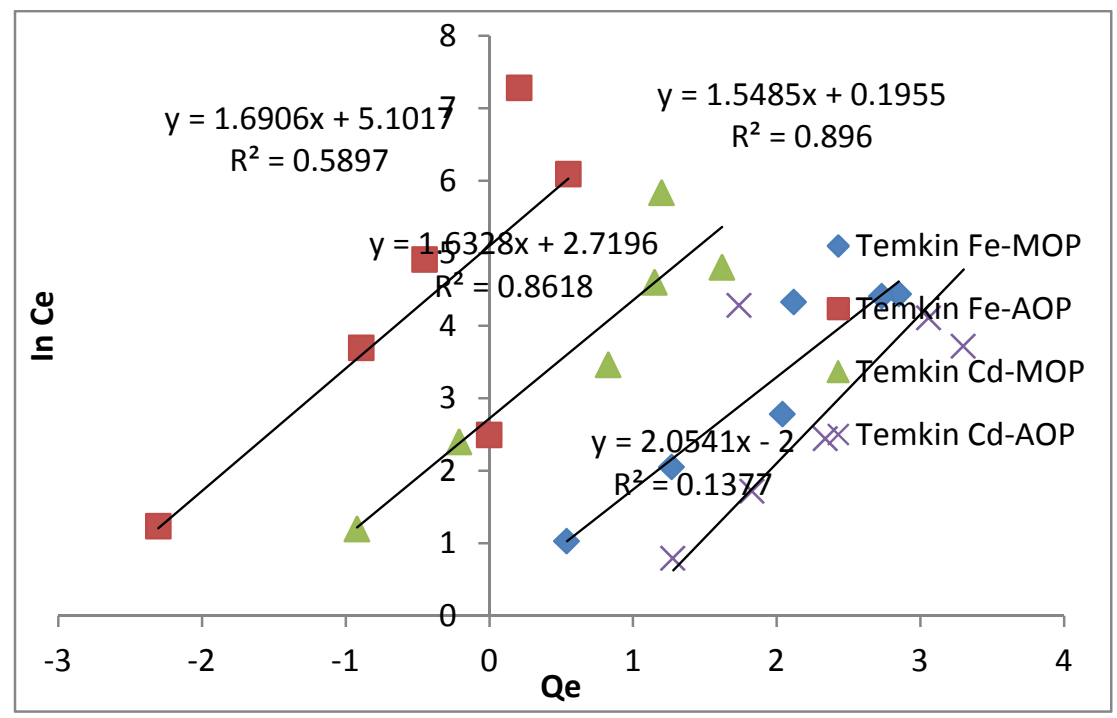

Fig. 8: Temkin isotherm for $\mathrm{Fe}$ and $\mathrm{Cd}$ adsorption on MOP and AOP

Table 3: Langmuir, Freundlich and Temkins constants for the adsorption of $\mathrm{Fe}$ (II) and $\mathrm{Cd}(\mathrm{II})$ ion on MOP and AOP.

\begin{tabular}{llllll}
\hline & & Fe & \multicolumn{3}{c}{ Cd } \\
\hline \multirow{4}{*}{ Freudlich } & & MOP & AOP & MOP & AOP \\
& $\mathrm{K}_{\mathrm{f}}(\mathrm{mg} / \mathrm{g})$ & 0.838 & 4.750 & 2.316 & 0.669 \\
& $\mathrm{~N}(\mathrm{~L} / \mathrm{mg})$ & 1.595 & 1.882 & 1.740 & 1.740 \\
& $\mathrm{R}^{2}$ & 0.910 & 0.695 & 0.916 & 0.49 \\
Langmuir & $\mathrm{a}(\mathrm{mg} / \mathrm{g})$ & 6.900 & 9.110 & 6.870 & 6.200 \\
& $\mathrm{~b}(\mathrm{mg} / \mathrm{g})$ & 0.114 & 2.45 & 0.604 & 0.068 \\
& $\mathrm{R}^{2}$ & 0.895 & 0.891 & 0.894 & 0.627 \\
& $\mathrm{~K}_{\mathrm{f}}(\mathrm{mg} / \mathrm{g})$ & 1.135 & 20.44 & 5.290 & 1.230 \\
& $\mathrm{~b}$ & 1.685 & 1.540 & 1.590 & 2.250 \\
& $\mathrm{R}^{2}$ & 0.896 & 0.589 & 0.860 & 0.410 \\
\hline
\end{tabular}

Adsorption Kinetics: Kinetic models are used to examine the rate of the adsorption process and potential rate controlling step. In this study, the kinetic data obtained from batch studies was analyzed by pseudo first and second order linear form as shown in table 4 below.

Pseudo First Order: The pseudo-first order is mathematically represented as follows:

$\log \left(\mathrm{q}_{\mathrm{e}}-\mathrm{q}_{\mathrm{t}}\right)=\log \mathrm{q}_{\mathrm{e}}-\left(\mathrm{k}_{1} / 2.303\right) t \ldots \ldots .(7)$

$t / q t=1 / k_{2} q_{e}^{2}+1 / q_{t}$

where $k_{1}$ is the pseudo-first order rate constant. The slope and intercept of the plot of $\log \left(\mathrm{q}_{\mathrm{e}}-\mathrm{q}_{\mathrm{t}}\right) \mathrm{vs} \mathrm{t}(\mathrm{mins})$ for adsorption of metal ions were used to determine the value of $\mathrm{k}$ and $\mathrm{q}_{\mathrm{e}}$ respectively. The pseudo-second order kinetic model has been widely used for adsorption systems due to its good representation of the experimental data for most of the adsorbent -adsorbate systems (Ho and Mckay, 1998). The model has the following merits: it does not have the problem of assigning an effective adsorption capacity, the adsorption capacity, rate constant of pseudo-second-order model and the initial adsorption rate all can be determined from the equation without knowing any parameter beforehand.

Pseudo-Second-Order: Adsorption kinetics was explained by the pseudo-second-order model as follows (Ho and Mckay,1998) 
$\frac{d q}{d t}=K_{2}\left(q_{e}-q_{t}\right)^{2}$

After integration;

$t / q t=1 / k_{2} q_{e}^{2}+\left(1 / q_{e}\right) t$

Where $\mathrm{k}_{2}$ is the pseudo-second-order rate constant $\left(\mathrm{g} \cdot \mathrm{mg}^{-1} \cdot \mathrm{min}^{-1}\right)$ and $\mathrm{q}_{\mathrm{e}}\left(\mathrm{mg} \cdot \mathrm{g}^{-1} \cdot \mathrm{min}^{-1}\right)$ can be calculated from the intercept and slope of plotting $t / q_{t} v s t$

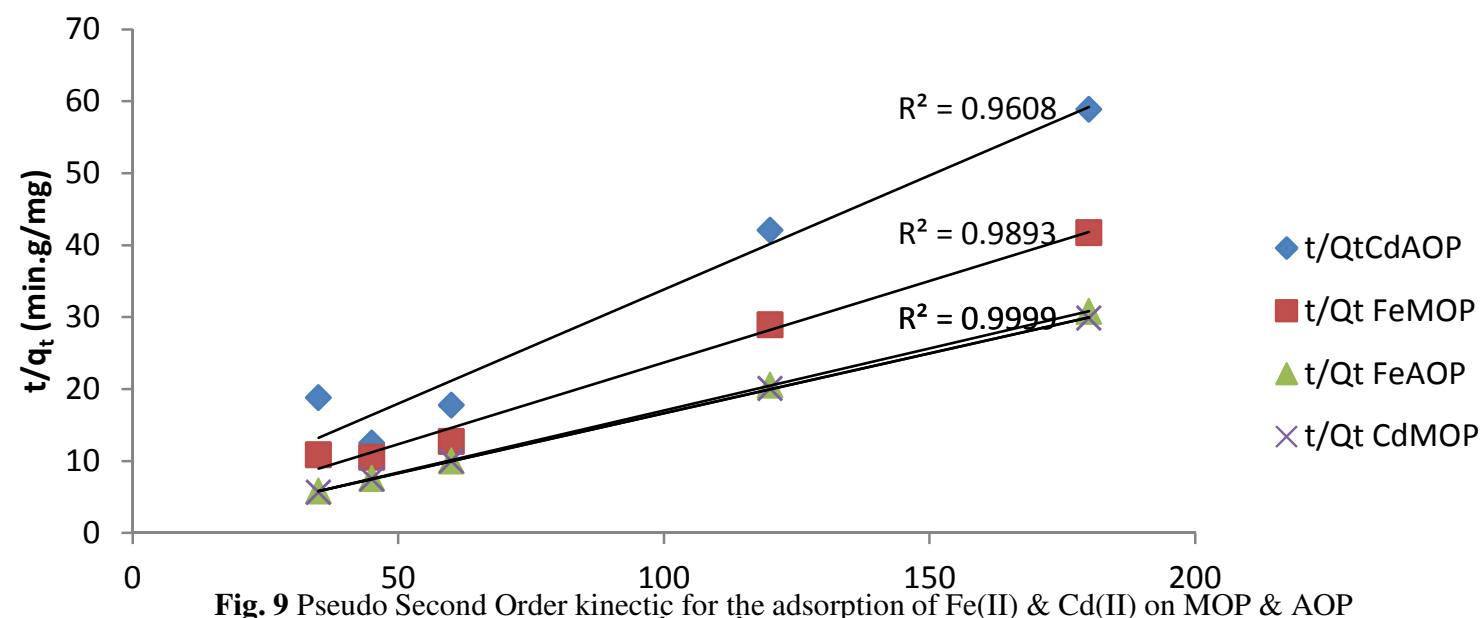

Fig. 9 Pseudo Second Order kinectic for the adsorption of Fe(II) \& Cd(II) on MOP \& AOP

Table 4: Pseudo first and second order kinetic constants for the adsorption of $\mathrm{Fe}$ (II) and $\mathrm{Cd}(\mathrm{II})$ on MOP and AOP

\begin{tabular}{llllll}
\hline & & Fe & & Cd & \\
\hline \multirow{3}{*}{ Pseudo first order } & & MOP & AOP & MOP & AOP \\
kinetics & $\mathrm{Q}_{\mathrm{e}}(\mathrm{mg} / \mathrm{g})$ & 1.496 & 3.61 & 0.05 & 6.36 \\
& $\mathrm{~K}_{1}$ & -0.014 & 0.01 & 0.023 & -0.023 \\
Pseudo Second order & $\mathrm{R}^{2}$ & 0.347 & 0.763 & 0.175 & 0.816 \\
kinetics & $\mathrm{Q}_{\mathrm{e}}$ & 4.41 & 5.79 & 5.998 & 3.15 \\
& $\mathrm{~K}_{2}$ & 0.05 & -0.13 & -0.96 & 0.05 \\
& $\mathrm{R}^{2}$ & 0.989 & 0.999 & 0.999 & 0.961 \\
\hline
\end{tabular}

The kinetic studies showed that the process obeyed a pseudo-second order rate expression, thus indicating a strong interaction between the bio-sorbent and adsorbent for both Metal-MOP and Metal-AOP adsorption.

Characterization of Adsorbent: Ftir Analysis: The adsorptive capacity of the samples (MOP and AOP) is influenced by its surface chemical structure. The functional groups suggested most often in activated carbons are carboxyl groups, phenolic hydroxyl groups, carbonyl groups and lactone groups (Ricordel et al., 2001). The FTIR spectra of MOP and AOP are shown in figure 10 below. 

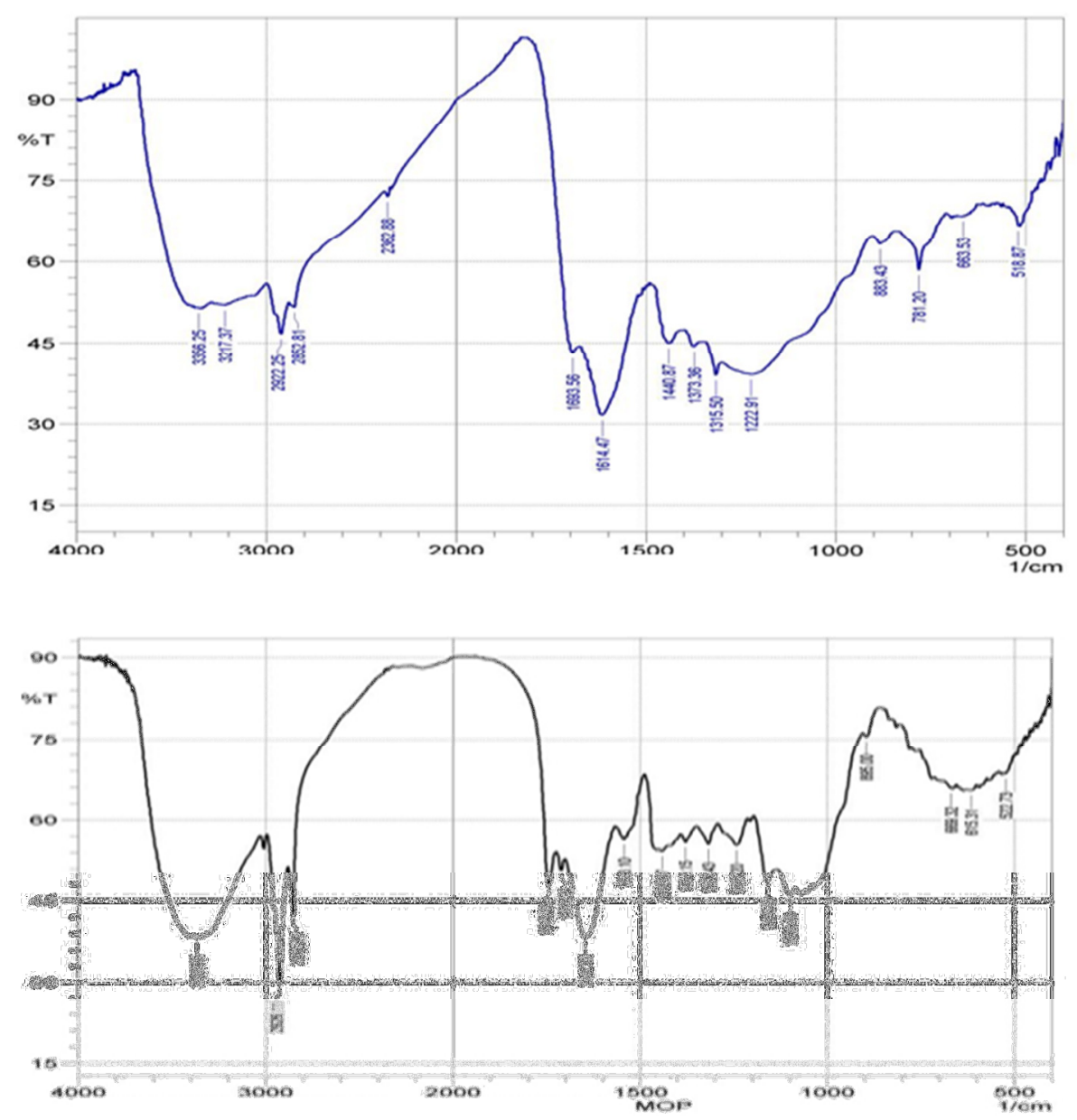

Fig. 10: FTIR Spectra for MOP and AOP

The spectra were recorded from $4000 \mathrm{~cm}^{-1}$ to $500 \mathrm{~cm}^{-1}$. The FTIR spectrum of both AOP and MOP with bands 3356 and 3369 respectively was attributed to $\mathrm{v}(\mathrm{O}-\mathrm{H})$ vibrations in hydroxyl group compared to the result reported elsewhere (Daffalla et al., 2010). The location of hydrogen-bonded $\mathrm{OH}$ groups is usually in the range of $3200-3650 \mathrm{~cm}^{-1}$ for alcohols and phenols. The band located around 2930 and $2850 \mathrm{~cm}^{-1}$ correspond to $\mathrm{v}(\mathrm{C}-\mathrm{H})$ vibration indicate the presence of alkane functional group compared to $2925 \mathrm{~cm}^{-}$ ${ }^{1}$ obtained elsewhere. (Daffalla et al.,2010). Orange peel (Cellulose-containing natural adsorbent) containing variety of functional groups that facilitates metal complexation which helps for the sequestering of heavy metals ( Sud et al., 2008); The high efficiency and selectivity for complexation with metal ions may be due to large numbers of hydroxyl and amino groups; primary amino groups provide high reactivity and the polymer chains provide suitable configuration as reported for agricultural natural adsorbent elsewhere (Sud et al., 2008).
Sem Analysis: Activated carbon prepared from orange peel (AOP) and acidic modified orange peels were observed by using electron microscope (SEM). The successive micrograph of thermal treated orange peel (AOP) and acidic modified orange peel (MOP) were shown in fig. 11 below. The SEM micrograph revealed that micro-porous structures, heterogeneous, rough surface with crater-like pores. SEM also revealed that the particles are of irregular shape and its surface exhibits a micro-rough texture, which can promote the adherence of cadmium and Iron.

The morphology of AOP showed that the surface was highly porous compared to MOP, because the structure of AOP was destroyed by heat and converted to very small particles with large surface area. For orange peel modified by Citric acid, the porosity also increased compared to activated Carbon AOP, because the acid removed the inorganic compounds such as carbonate and silica from the surface of adsorbent (Daffalla et al., 2011) 

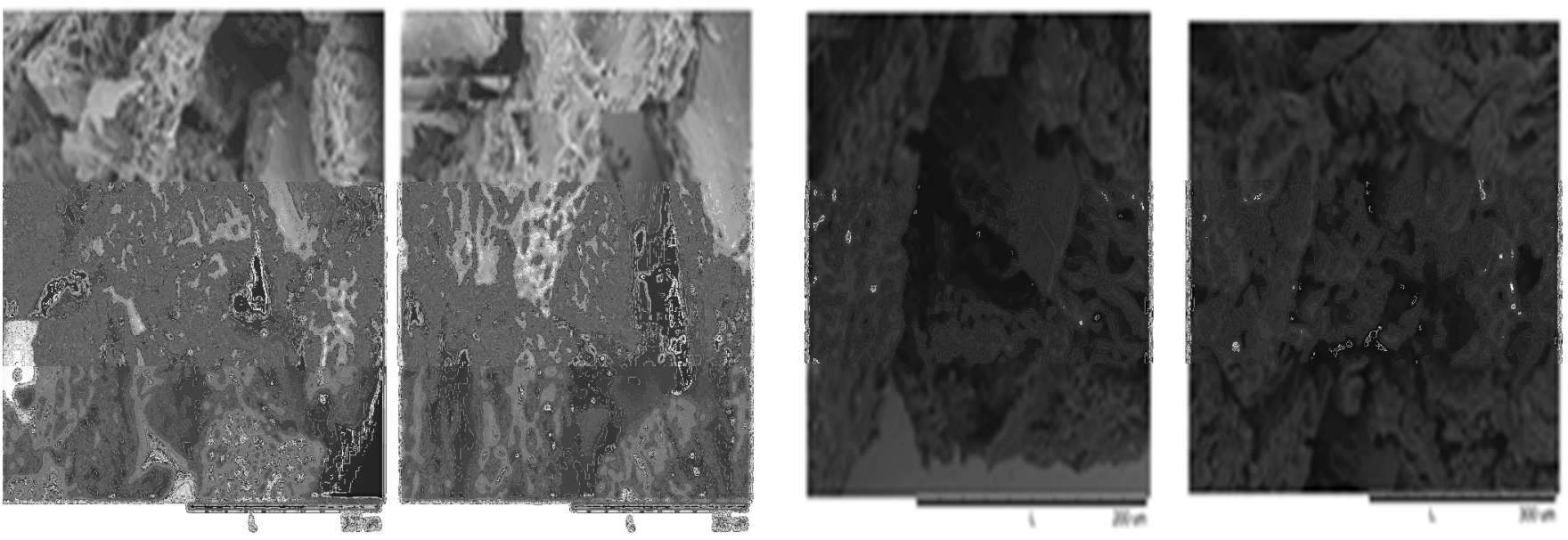

Fig. 11: SEM pictures of AOP and MOP

Conclusion: Low cost adsorbents are eco-friendly and efficient for removal of heavy metals in soil, waste water and aqueous solution. This $\mathrm{pH}$ dependent Modified Orange Peel sample could be used as an adsorbent for the effective removal of both $\mathrm{Fe}$ (II) and $\mathrm{Cd}(\mathrm{II})$ ions from aqueous solution. The adsorption isotherms which fitted well into Freundlich model reveal a heterogeneous phase adsorption. The modified orange peel had the best overall performance due to the presence of citric acid which aid binding during adsorption.

\section{REFERENCES}

Acar, FN; Eren Z (2006) Removal of Cu (II) ions by activated poplar sawdust (Samsun Clone) from aqueous solutions. J. Hazard. Mater., B 137: 909

Agbozu, IE; Emoruwa, FO (2014) Batch adsorption of heavy metals $(\mathrm{Cu}, \mathrm{Pb}, \mathrm{Fe}, \mathrm{Cr}$ and $\mathrm{Cd})$ from aqueous solutions using coconut husk Afri. J. of Environs. Sci. Tech., 8(4): 239 - 246.

Adegoke, HI, Addekola, FA (2010) Removal of Phenol from Aqueous Solution by Activated Carbon Prepared from Some Agricultural Materials. Adv. in Nat. Appli. Sci., 4(3): 293-298.

Bulut, Y.; Tez Z. (2007) Adsorption studies on ground shells of hazelnut and almond. $\boldsymbol{J}$. Hazard. Mater., 149: 35 - 41
Bulut, Y; Baysal, Z (2006) Removal of Pb (II) from wastewater using wheat bran. $J$. environs . Manage.,78: 107 - 113.

Daffalla, SB; Mukhtar, H;Shaharun, MS (2010) Characterization of Adsorbent Developed from Rice Husk: Effect of Surface Functional Group on Phenol Adsorption. J. Appl. Sci., 10 : 1060 - 1067.

Dorris, K L; Zhang, Y; Shukla, A; Shukla, SS; Yu B (2000) The removal of heavy metal from aqueous solutions by sawdust adsorption - removal of copper. J. Hazard. Mater. B80 (1-3) : 33 - 42.

Elaigwu, SE; Usman, LA; Awolola, GV;Adebayo, GB; Ajayi RMK. (2009) Adsorption of $\mathrm{Pb}$ (II) from Aqueous Solution by Activated Carbon Prepared from Cow Dung. Adv. in Nat. Appl. Sci., 3(3): 442 - 446.

Giwa, AA; Bello, IA; Oladipo, MA ;Adeoye D (2013) Removal of Cadmium from waste water by Adsorption using Husk of melon (Citrulluslanatus) seed .Int. J. Bas. Appl. Sci., 2(1): 110 - 123

Hanif, MA; Bhatti, HN; Ali, MA (2010) Heavy metal tolerance and biosorption potential of white rot fungi. Asian J. Chem., 22: 335 - 345. 
Ho, YS; McKay, G (1999) Pseudo-second order model for sorption processes. Proces. Biochem., 34:451 - 465.

Itodo, AU; Abdulrahman, FW; Hassan, LG; Maigandi, SA Itodo, HU (2010). Physicochemical Parameters of Adsorbent from Locally Sorted $\mathrm{H}_{3} \mathrm{PO}_{4}$ and $\mathrm{ZnC}$ Modified Agricultural wastes. J. of New

York Sci., 5:17 -24

Jothinayagi, N; Anbazhagan, C (2009) Heavy Metal Monitoring of Rameshwaram Coast by some Sargassum species.American-Eurasian J. Sci. Res., 4 : 73-80.

Krishnani, KK; Mengb, X; Christodoulatos, C ;Bodduc, VM (2008) Biosorption mechanism of nine different heavy metals onto biomatrix from rice husk. J. Hazard. Mater, 153:1222 - 1234.

Muneer, M ; Bhatti, IA.; Adeel, S (2010) Removal of $\mathrm{Zn}, \mathrm{Pb}$ and $\mathrm{Cr}$ in textile wastewater using rice husk as a biosorbent. Asian J. Chem., 22: 7453 - 7459 .

Okoli, J; Ezuma I (2014) Adsorption Studies of Heavy Metals by Low-Cost Adsorbents management.J. Appl. Sci Environ. Manage., 18(3): $443-448$.

Patnukao, P; Kongsuwan, A; Pavasant, P (2008) Batch studies of adsorption of copper and $\mathrm{Pb}$ (II) on activated carbon from Eucalyptus camaldulensisDehn. Bark. J. Environ. Sci., 20: $1028-1034$

Radhika, V; Subramanian S; Natarajan, KA (2006) Bioremediation of zinc using Desulfotom aculumnigrificans: Bioprecipitation and characterization studies. Water Res., 40(19): $3628-3636$.
Ricordel, S; Taha, S;Ciss e, I; Dorange, G (2001) Heavy metals removal by adsorption onto peanut husks carbon: Characterization, kinetic study and modeling Sep Purif. Technol., 24 (3) : 389- 401

Singh, SR; Singh, AP (2014) Treatment of water Rice husk carbon as a new low cost adsorbent. Int.J of Environ Res., 6 (4) : 917 - 924.

Sud, D;Mahajan, G; Kaur, MP (2008) Agricultural waste material as potential adsorbent for sequestering heavy metal ions from aqueous solutions- A review. Biores Techn., 99: $6017-6027$.

Walter, GM; Hanna, JA; Alen, SJ (2005). Treatment of Hazardous Shipyard Wastewater Using Dolomitic Adsorbent. Wat Res., 39: 242 -2428.

Wang, SB; Boyjoo, Y; Choueib, A (2005) Zeolitization of fly ash for sorption of dyes in aqeousssolutions. Studies in surf. Sci., and cataly $158: 161-168$.

Wase, DA; Forster, CF (1997) Biosorbents for Metal Ions. Taylor and Francis, London.

Wiwid, PP; Azlan, K; Siti, NMY; Che, FI;Azmi M, Norhayati H; Illyas MI (2014) Biosorption of $\mathrm{Cu}(\mathrm{II}), \mathrm{Pb}(\mathrm{II})$ and $\mathrm{Zn}(\mathrm{II})$ Ions from Aqueous Solutions Using Selected Waste Materials: Adsorption and Characterisation Studies. J. of Encap and Adsor. Sci. 4: 2535 